\title{
Qualidade do leite proveniente de propriedades com diferentes níveis de especialização
}

\section{Milk quality from properties with different level of specialization}

\author{
Flávio José Simioni ${ }^{1 *}$; Carolina Riviera Duarte Maluche Baretta ${ }^{1}$; \\ Lenita Moura Stefani²; Leandro Sâmia Lopes ${ }^{1}$; Tarciso Tizziani ${ }^{3}$
}

\begin{abstract}
Resumo
O trabalho foi realizado com o objetivo de avaliar os parâmetros de qualidade do leite segundo três níveis de especialização das unidades de produção de leite de diferentes municípios do Oeste Catarinense. A caracterização das unidades de produção de leite foi realizada utilizando-se um questionário em 29 propriedades rurais como instrumento de coleta de dados, aplicado durante a visita à propriedade rural. Também foram coletadas 58 amostras de leite dos tanques de resfriamento para a determinação dos níveis de gordura, proteína, lactose, contagem de células somáticas (CCS) e contagem bacteriana total (CBT). Considerando-se as informações obtidas, as unidades de produção de leite foram classificadas em: especializado (E), semiespecializado (SE) e não especializado (NE). Os dados foram submetidos a métodos multivariados de análise estatística, com o emprego da Análise de Componentes Principais (ACP) e da Análise de Redundância (RDA). Os resultados das análises indicam que o tempo na atividade, a área com pastagem perene, a renda bruta com bovinos de leite, o tipo de ordenha, a lavagem dos tetos e o método de reprodução são as variáveis que mais interferem na qualidade do leite. O aumento do nível de especialização da atividade leiteira, mesmo produzindo menor porcentagem de gordura e proteína no leite, proporciona a obtenção de leite de melhor qualidade, devido aos menores índices de CCS e CBT, associadas principalmente, à maior renda proporcionada pela atividade. Nas propriedades especializadas, a atividade leiteira apresenta maior importância econômica, estimulando o produtor a adotar melhores práticas de higiene na ordenha e de reprodução do rebanho.

Palavras-chave: Composição do leite, ordenha, práticas de higiene, renda do leite
\end{abstract}

\begin{abstract}
This work was aimed to evaluate milk quality parameters according to three levels of specialization of milk production units in different districts of West Santa Catarina's State, Brazil. Characterization of milk production units was carried out using a questionnaire in 29 farms as a tool for data collection, applied during a visit to the farm. At the time, 58 milk samples were collected from cooling tanks to determine the levels of fat, protein, lactose, somatic cell count (SCC) and total bacteria count (TBC). Considering the information obtained the milk production units were classified as specialized $(\mathrm{E})$, semi-specialized (SE) and not specialized (NE). The database was subjected to multivariate methods of statistical analysis with the use of Principal Component Analysis (PCA) and Redundancy analysis (RDA). The results indicated that variables that most influence milk quality are: time in the activity, area with perennial pasture, gross income from milk activity, type of milking, teat washing and method

\footnotetext{
${ }^{1}$ Profs. do Dept ${ }^{\circ}$ de Zootecnia, Universidade do Estado de Santa Catarina, CEO/UDESC, Chapecó, SC. E-mail: fjsimioni@, hotmail.com; carolmaluche@bol.com.br; leandrosamia@yahoo.com.br

${ }^{2}$ Prof $^{\mathrm{a}}$ do Dept ${ }^{\mathrm{o}}$ de Zootecnia e do Mestrado em Ciência Animal, Centro de Ciências Agroveterinárias CAV/UDESC, Lages, SC. E-mail: lenita.stefani@udesc.br

${ }^{3}$ Discente, Bolsista de Iniciação Científica do Dept ${ }^{\circ}$ de Zootecnia, CEO/UDESC, Chapecó, SC. E-mail: tarciso@zootecnista.com.br * Autor para correspondência
} 
of reproduction. Results showed that despite lower percentages of fat and protein, the increased level of specialization provides milk of better quality due to the low rates of SCC and TBC, which leads to higher income from this type of activity. In specialized farms where milk activity has a high economic importance, producers are encouraged to adopt better hygiene practices during milking and herd breeding.

Key words: Milk composition, milking, hygiene practices, income from milk

\section{Introdução}

É consenso entre pesquisadores e analistas de mercado, que os consumidores estão se tornando cada vez mais exigentes quanto à qualidade dos alimentos, graças à maior percepção do papel exercido por estes e seus componentes sobre a saúde humana. Em relação ao leite, novos padrões de qualidade estão sendo exigidos, abrindo novos mercados por meio da diferenciação do produto.

De acordo com Ribeiro, Stumpf Júnior e Buss (2000), o leite de qualidade deve apresentar composição química (sólidos totais, gordura, proteína, lactose e minerais), microbiológica (contagem bacteriana total), organoléptica (sabor, odor, e aparência) e número de células somáticas que atendam os parâmetros exigidos internacionalmente.

No Brasil, o Ministério da Agricultura, Pecuária e Abastecimento publicou em 2002 a Instrução Normativa 51 (IN 51), fixando parâmetros para garantir o padrão de qualidade do leite, tais como requisitos físicos, químicos, microbiológicos, de contagem de células somáticas (CCS) e de resíduos químicos (BRASIL, 2002). A partir de então, muito se tem debatido a respeito do assunto e os dados históricos de análises de leite revelam a trajetória da evolução dos produtores em busca de um produto de melhor qualidade.

Estudos realizados por Fassio et al. (2005) e Gomes e Ferreira Filho (2007) demonstraram que a escala de produção de leite influencia os custos unitários. Vários pesquisadores, tais como, Rodas et al. (2000), Gonzalez (2002), Gonzalez et al. (2006), Martins et al. (2007) e Zanela et al. (2006) apresentaram resultados que demonstram a existência de relação significativa entre o nível de especialização e os parâmetros de qualidade do leite.

Diante do exposto, objetivou-se com este trabalho, estudar a relação existente entre os diferentes níveis de especialização produtiva e os parâmetros de qualidade do leite na região oeste do estado de Santa Catarina.

\section{Material e Métodos}

A pesquisa foi realizada pelo Departamento de Zootecnia da Universidade do Estado de Santa Catarina - CEO/Chapecó em diferentes municípios da região do Oeste Catarinense (Campo Erê, Caxambu do Sul, Chapecó, Coronel Freitas, Dionísio Cerqueira, Guatambu, Nova Erechim, Nova Itaberaba, Quilombo, São José do Cedro, Saudades e Seara), entre os meses de dezembro de 2010 a fevereiro de 2011. Foram coletadas 58 amostras de leite de 29 unidades de produção, obtidas segundo os critérios de aleatoriedade e acessibilidade, objetivando contemplar as diferentes características regionais das unidades de produção.

Para determinar a qualidade do leite utilizaramse como parâmetros os teores de gordura, lactose, proteína, contagem bacteriana total (CBT) e contagem de células somáticas (CCS). As amostras de leite foram coletadas diretamente do tanque de resfriamento, durante as visitas às propriedades rurais. $\mathrm{O}$ procedimento de amostragem atendeu as recomendações da Rede Brasileira de Laboratórios de Controle de Qualidade do Leite (RBQL) e as análises foram realizadas pelo Laboratório Estadual de Qualidade do Leite do Centro Estadual de Pesquisa e Diagnóstico de Alimentos (CEPDA) da Universidade do Contestado (UNC) de Concórdia/SC. 
A caracterização das unidades de produção de leite foi realizada utilizando-se de um questionário como instrumento de coleta de dados, aplicado durante a visita à propriedade rural. Considerandose as informações obtidas, as unidades de produção de leite foram classificadas em três sistemas de produção: especializado (E), semiespecializado (SE) e não especializado (NE) (Adaptado de GONZALEZ et al., 2006; MARTINS et al., 2006). Para divisão dos sistemas de acordo com o nível de especialização foram atribuídos pontos levando-se em consideração a infraestrutura (sala de ordenha, tipo de ordenha, sala de espera dos animais e tipo de resfriador), manejo higiênico-sanitário (lavagem dos tetos, utilização de vestuário adequado, uso de pré-dipping e pós-dipping e controle de mastite utilizando-se o California Mastitis Test (CMT) e teste da caneca de fundo escuro, manejo profilático (controle de verminoses e uso das vacinas adequadas), tempo dedicado ao dia para a atividade leiteira e características socioeconômicas (escolaridade e idade) nas propriedades analisadas. Assim, as unidades de produção do sistema especializado ficaram com pontuação de um a 0,6 ; no sistema semiespecializado, de 0,5 a 0,3 e as unidades não especializadas obtiveram pontuações inferiores a 0,3 .

Das 29 propriedades analisadas, 14 foram classificadas como sistema E, sendo compostas por rebanhos especializados das raças Jersey ou Holandesa. Destas propriedades, 12 continham sala de ordenha do tipo espinha de peixe com fosso e duas apresentavam sala de ordenha pavimentada sem fosso; apenas uma propriedade não continha sala de espera pavimentada; 12 delas continham ordenha canalizada e duas com balde ao pé; e todas possuíam resfriador de expansão. Essas propriedades utilizavam técnicas de controle de mastite como prédipping e pós-dipping, teste CMT e caneca de fundo escuro e ainda, toalhas descartáveis para secagem dos tetos. Nove das propriedades utilizavam vestuário adequado e as demais não faziam uso de luvas e avental. Essas propriedades utilizavam vacinas e vermífugos para a prevenção das doenças mais comumente encontradas em bovinos de leite. Em apenas três propriedades, os produtores não possuíam ensino médio e atuavam a menos de cinco anos na atividade. O tempo dedicado na bovinocultura de leite foi superior a seis horas por dia em todas as propriedades.

O sistema SE foi composto por nove propriedades, sendo que apenas duas delas continham sala de ordenha pavimentada com fosso, e as demais possuíam sala de ordenha pavimentada sem fosso. Somente em duas propriedades havia sala de espera com pavimentação. Em todas as unidades, a ordenha era feita com balde ao pé; e cinco propriedades continham resfriador de expansão e as demais de imersão. O manejo higiênico-sanitário não foi composto de todas as medidas técnicas recomendadas. A utilização de qualquer tipo de vestuário foi inexistente. $\mathrm{O}$ controle de verminose estava presente em todas as propriedades, no entanto, nem todas as vacinas necessárias eram aplicadas. Apenas duas propriedades encontravamse a menos de cinco anos na atividade. Já o tempo dedicado na bovinocultura de leite não foi superior a seis horas diárias e, em cinco propriedades a mãode-obra não possuía ensino fundamental completo.

Seis propriedades se enquadraram como sistema $\mathrm{NE}$, sendo que quatro delas continham sala de ordenha pavimentada sem fosso e, duas encontravase sem pavimentação. Em cinco propriedades a ordenha era realizada com balde ao pé e uma com ordenha manual, sendo que três delas possuíam resfriador de expansão e as demais de imersão. O manejo higiênico-sanitário era mínimo, com ausência da maioria das técnicas recomendadas e sem a utilização de qualquer vestuário. Em cinco propriedades havia controle de verminose, porém, não se verificou a aplicação das vacinas necessárias. Todas as unidades encontravam-se a mais de cinco anos na atividade, sendo que o tempo dedicado ao dia não passava de três horas em duas delas. Em duas propriedades havia formação no ensino médio. 
As variáveis respostas (GORD - teor de gordura, PROT - proteína, LACT - lactose, CCS contagem de células somáticas e CBT - contagem bacteriana total) e as variáveis explicativas (TEMP - tempo na atividade, VACA - número de vacas em lactação, ANIM - número total de animais leiteiros, PAAN - área com pastagem cultivada anual, PAPE - área com pastagem perene, RBLE renda bruta com bovinos de leite, UTH - unidade de trabalho homem, PAST - tipo de pastejo, VERM frequência do controle de verminose, ORDE - tipo de ordenha, AGUA - uso de água quente, CANE teste da caneca, LAVA - lavagem dos tetos, PRED - pré-dipping, TOAL - uso de toalhas descartáveis, REPA - faz repasse, POSD - pós-dipping, CMT - uso do teste CMT, RACA - fornecimento de ração, REPR - método de reprodução, SEME - uso de sêmen, ACAS - acasalamento, RESF tipo de resfriador) foram submetidas a métodos multivariados de análise estatística com o objetivo de detectar e representar a estrutura subjacente aos dados, com a vantagem de analisar todas as variáveis simultaneamente.

As variáveis respostas foram utilizadas para obtenção do comprimento do gradiente, e seleção do modelo de resposta, a partir do programa CANOCO versão 4.6 (TER BRAAK; SMILAUER, 1998). Como este gradiente foi menor do que três (resposta linear), optou-se pela Análise de Componentes Principais (ACP - Principal Component Analysis). A ACP é uma técnica de ordenação linear utilizada para auxiliar a reduzir diferenças entre os tratamentos, dando importância ao peso das variáveis explicativas na contribuição das diferenças entre os tratamentos (TER BRAAK; PRENTICE, 1988).

A ACP é uma análise de gradiente indireta que se inicia com uma ordenação normal onde os valores (coordenadas) de um eixo particular podem ser interpretados como gradiente de uma variável explicativa. As variáveis explicativas não são utilizadas diretamente para prever as diferenças entre os tratamentos, mas são adicionadas posteriormente para ajudar a responder os dados obtidos.

Complementando o objetivo de verificar as diferenças obtidas entre os níveis de especialização e verificando as possíveis relações existentes entre as variáveis respostas obtidas em cada tratamento e possíveis variáveis explicativas, foi realizada uma técnica de ordenação conhecida como Análise de Redundância (AR - Redundancy Analysis), com os dados transformados de acordo com a equação: $\mathrm{x}=\log (\mathrm{x}+1)$. A AR é uma ordenação de dados de resposta de gradiente direta nos quais os eixos são construídos para serem combinações lineares de variáveis respostas, utilizada para detectar e prever a estrutura subjacente aos dados com base em variáveis explicativas. As análises de gradiente direta iniciam-se com dois conjuntos de dados que são representados no mesmo diagrama, onde as relações entre os dois conjuntos de variáveis são derivadas desse diagrama (o diagrama representa a variabilidade explicada pelas variáveis explicativas). Há um input direto das variáveis explicativas em um estado inicial da análise, que servem para responder as possíveis correlações entre as variáveis.

A significância das correlações sugeridas pela RDA foi obtida por meio do coeficiente de correlação de Spearman (ZAR, 1996). Inicialmente, a análise foi realizada utilizando todas as variáveis explicativas selecionadas para o modelo. Devido à ausência de significância medida através de permutações pelo teste de Monte Carlo realizouse uma Forward Selection. Através da Forward Selection foram eliminadas as variáveis com efeito de colinearidade e através dos resultados obtidos para Marginal effects e Conditional effects foram selecionadas apenas as variáveis significativas para a análise: TEMP - tempo na atividade, ORDE tipo de ordenha, LAVA - lavagem dos tetos, PAPE - área com pastagem perene, REPR - método de reprodução e RBLE - renda bruta com bovinos de leite. Todas as análises foram realizadas utilizandose o programa CANOCO versão 4.6 (TER BRAAK; SMILAUER, 1998). 


\section{Resultados e Discussão}

Considerando os parâmetros descritivos de qualidade do leite (Tabela 1), verificou-se tendência de redução dos níveis de proteína e gordura à medida que se aumentou o nível de especialização produtiva. Entretanto, para as demais variáveis respostas não se percebeu uma clara tendência no comportamento dos dados, exceto para a variável CBT que apresentou significativa redução no nível especializado de produção.

Tabela 1. Valores médios das variáveis respostas segundo o nível de especialização.

\begin{tabular}{|c|c|c|c|c|c|c|}
\hline \multirow{3}{*}{ Variáveis respostas } & \multicolumn{6}{|c|}{ Nível de Especialização } \\
\hline & \multicolumn{2}{|c|}{ NE } & \multicolumn{2}{|c|}{ SE } & \multicolumn{2}{|c|}{$\mathrm{E}$} \\
\hline & Média & DP & Média & DP & Média & DP \\
\hline GORD - Teor de gordura (\%) & 3,92 & 0,28 & 3,72 & 0,40 & 3,52 & 0,38 \\
\hline PROT - Teor de proteína (\%) & 3,27 & 0,32 & 3,19 & 0,16 & 3,15 & 0,19 \\
\hline LACT - Teor de lactose $(\%)$ & 4,39 & 0,09 & 4,44 & 0,15 & 4,43 & 0,14 \\
\hline $\mathrm{CCS}-(\mathrm{x} 1000 \mathrm{CS} / \mathrm{mL})$ & 462,33 & 126,11 & 607,44 & 398,13 & 494,26 & 225,08 \\
\hline $\mathrm{CBT}-(\mathrm{x} 1000 \mathrm{UFC} / \mathrm{mL})$ & 333,33 & 214,96 & 967,78 & 978,74 & 77,79 & 86,62 \\
\hline
\end{tabular}

Nota: CCS - contagem de células somáticas e CBT - contagem bacteriana total.

Fonte: Elaboração dos autores.

A explicação para este comportamento pode ser devido a melhoria da nutrição dos animais e utilização de raças especializadas com o aumento nos níveis de especialização. Já a concentração de proteína no leite apresentou declínio à medida que o sistema de produção se tornou mais especializado. Porém, de acordo com alguns dados de literatura, há pouca variação na concentração de proteína no leite conforme o tipo de sistema adotado (KITCHEN, 1981; HARMON, 1994; SCHAELLIBAUM, 2000).

Em sistemas mais especializados ocorre maior utilização de alimentos concentrados para atender a maior exigência nutricional dos animais, e na composição desses alimentos concentrados, há maior concentração de ácidos graxos insaturados quando comparado às forragens comumente utilizadas nos sistemas menos especializados, o que leva à diminuição na concentração de gordura do leite. Este fenômeno é conhecido como síndrome da depressão do leite, onde todos os ácidos graxos de cadeia longa que fazem parte da gordura do leite provêm da biohidrogenação no rúmen, ocasionada pela bactéria Butyrivibrio fibrisolvens que altera a síntese de alguns isômeros do ácido linoleico conjugado (CLA) (GONZALEZ, 2004).

A principal ação dos ácidos graxos trans-10 na depressão da gordura do leite é devido a depressão da expressão gênica das enzimas relacionadas ao metabolismo lipídico. De acordo com Baumgard et al. (2002), o CLA trans-10, cis-12 tem a capacidade de deprimir a expressão gênica da enzima lipase lipoprotéica (responsável pela hidrólise e liberação dos ácidos graxos para serem utilizados pelas células), da enzima delta 9-dessaturase (enzima envolvida na síntese de ácidos graxos monoinsaturados) e principalmente da enzima acetil-COA carboxilase (que catalisa a síntese do malonil-COA, responsável pelo início da biossíntese de ácidos graxos) em aproximadamente 66,75 e $72 \%$, respectivamente.

Em termos gerais, a qualidade do leite pode ser relacionada com sua população bacteriana (CBT menor que $750.000 \mathrm{UFC} / \mathrm{mL}$ ) e baixa concentração de células somáticas (CCS abaixo de 750.000 cel./ $\mathrm{mL}$ ), de acordo com o padrão estabelecido pela IN 51/2002 (BRASIL, 2002). Destaca-se que a partir de janeiro de 2012 para as regiões Sul, Sudeste e Centro-Oeste, novos limites entraram em vigor, 
sendo CBT menor que $100.000 \mathrm{UFC} / \mathrm{mL}$ e CCS abaixo de 400.000 cel./mL (BRASIL, 2011). O leite dentro do úbere da vaca é estéril, ou seja, não contêm bactérias. Porém, se o animal estiver infectado por alguma doença, principalmente na glândula mamária, é possível que o leite se contamine ainda dentro do úbere (BRAMLEY; McKINNON, 1990).

Este trabalho evidenciou que $13,8 \%$ das propriedades analisadas não atingiram o padrão da IN 51 atualmente em vigor, sendo que este percentual seria de $55,1 \%$ e $51,8 \%$ considerando os novos padrões de CCS e CBT, respectivamente. Pode se inferir que os produtores pesquisados terão ainda muito a evoluir quanto a este quesito, podendo se traduzir em aumento da lucratividade caso fossem remunerados de acordo com os parâmetros de qualidade do leite e adotadas algumas estratégias para diminuir a CCS, tais como o protocolo para tratamento de mastite.

A CBT no leite é um teste empregado para avaliar a qualidade do leite, que fornece indicativos dos cuidados de higiene empregados na obtenção e manuseio durante a produção. Sendo assim, altas contagens bacterianas indicam falhas na limpeza dos equipamentos, na higiene da ordenha ou problemas na refrigeração do leite. Verificou-se também que apenas o sistema especializado de produção de leite apresentou CBT abaixo de 100.000 UFC/ $\mathrm{mL}$. Pode-se associar este resultado aos manejos técnicos e higiênicos adotados por este tipo de sistema, como utilização de ordenhadeira mecânica, tanques de resfriamento com temperatura adequada de armazenamento, higienização do encanamento da ordenhadeira, dentre outras práticas de higiene na ordenha.

Células somáticas são células presentes no leite, que incluem as células originárias da corrente sanguínea como leucócitos e células de descamação do epitélio glandular secretor (PHILPOT;
NICKERSON, 1991). Dessa forma, a CCS no leite ou no tanque de expansão é uma ferramenta valiosa na avaliação do nível de mastite subclínica do rebanho, que pode causar inúmeros prejuízos aos produtores, principalmente devido à diminuição na produção de leite, gastos com medicamentos e até mesmo a eliminação da vaca do rebanho. Além disso, leite com alta CCS, quando destinado à produção de derivados, pode acarretar alterações na qualidade dos produtos finais, que resulta em redução na produção industrial, aumento do tempo de coágulo, e alterações negativas na qualidade sensorial (KITCHEN, 1981).

A contaminação do leite também pode ocorrer pelo contato com os equipamentos (teteiras, tubulação, tanque de resfriamento, etc.), que não foram higienizados de forma eficiente. Um dos métodos mais eficientes para controle bacteriano no leite é o resfriamento, pois no momento da ordenha o mesmo se encontra em temperatura de aproximadamente $37^{\circ} \mathrm{C}$ e é resfriado rapidamente para $4^{\circ} \mathrm{C}$, para que as bactérias diminuam sua taxa reprodutiva, pois em condições favoráveis de crescimento podem duplicar sua população a cada 15 minutos, e o leite se tornar inadequado em aproximadamente quatro horas após a ordenha (SILVA et al. 2010).

A Análise de Componentes Principais (ACP) para os sistemas de produção apresentou 43,9\% da sua variabilidade explicada pelas variáveis ambientais TEMP, PAPE, RBLE, ORDE, LAVA e REPR. Deste valor, a dimensão um, ou componente principal um, explicou $43,5 \%$ da variabilidade dos dados. Já a dimensão dois ou componente principal dois, explicou $18,8 \%$, enquanto que a dimensão três ou componente principal três, explicou $18,2 \%$ e, por fim, a dimensão quatro ou componente principal quatro explicou $11,2 \%$ da variabilidade restante, totalizando $91,7 \%$ da variabilidade total dos dados (Tabela 2). 
Tabela 2. Autovalores e explicação (\%) da variância para os componentes principais.

\begin{tabular}{cccc}
\hline Componente Principal & Autovalor (Eigen values) & \% da Variância & \% Acumulada \\
\hline 1 & 0,343 & 43,5 & 43,5 \\
2 & 0,251 & 18,8 & 62,3 \\
3 & 0,188 & 18,2 & 80,5 \\
4 & 0,120 & 11,2 & 91,7 \\
\hline
\end{tabular}

Fonte: Elaboração dos autores.

Devido à porcentagem de resposta obtida pelas duas primeiras dimensões (um e dois), que explicam conjuntamente $62,3 \%$ da variabilidade total dos dados acumulados, as discussões deste trabalho foram baseadas nas mesmas.

De maneira geral, o triplot das duas primeiras dimensões da ACP separou dois principais grupos ao longo do primeiro eixo. O grupo A reuniu os sistemas $\mathrm{SE}$ e NE, os quais apresentaram valores semelhantes para algumas variáveis estudadas, distinguindo-se do grupo B que representa o sistema E (Figura 1).

Os autovalores para as duas primeiras dimensões foram de 0,343 e 0,251, respectivamente. Já as dimensões três e quatro obtiveram autovalores de 0,188 e 0,120 , respectivamente (Tabela 2). Embora os sistemas SE e NE ficassem mais próximos entre si, quando comparados ao sistema $\mathrm{E}$, apresentaram comportamento diferentes. A ACP indicou que os valores altos encontrados para CCS e CBT estão associados às amostras do sistema SE (Figura 1). Este resultado pode ser explicado pelo fato de que este grupo de produtores não adotou as principais práticas de higiene, principalmente as relacionadas aos equipamentos de ordenha. São produtores que estão a mais tempo na atividade (16,3 anos) quando comparado aos demais grupos, porém sem incorporações de tecnologias, o que reflete a importância econômica secundária da atividade leiteira.

Isso é confirmado quando a ACP associou os elevados valores encontrados para CCS e CBT no sistema SE à variável tempo na atividade (TEMP) e aos menores valores para variáveis como RBLE (renda bruta com bovino), REPR (método de reprodução) e LAVA (lavagem dos tetos) (Figura 1). Pelo fato de que, para este grupo de produtores a atividade leiteira apresenta baixa participação na formação da renda (menores valores de RBLE), não se verifica investimentos em melhoramento genético via métodos de reprodução e na adoção de práticas de higiene. São fatores que explicam os altos níveis de CCS e CBT. São os produtores que estão a longo tempo na atividade, porém sem realizar investimentos e melhorias nas práticas de manejo, mantendo a atividade com baixa representação na renda da propriedade. 
Figura 1. Triplot das variáveis respostas através da análise de componentes principais (ACP) no plano definido pelas dimensões 1 e 2 . Valor médio dos componentes principais representados através dos centroides dos tratamentos ( $\mathrm{E}-$ $\mathrm{SE}-\mathrm{NE})$.

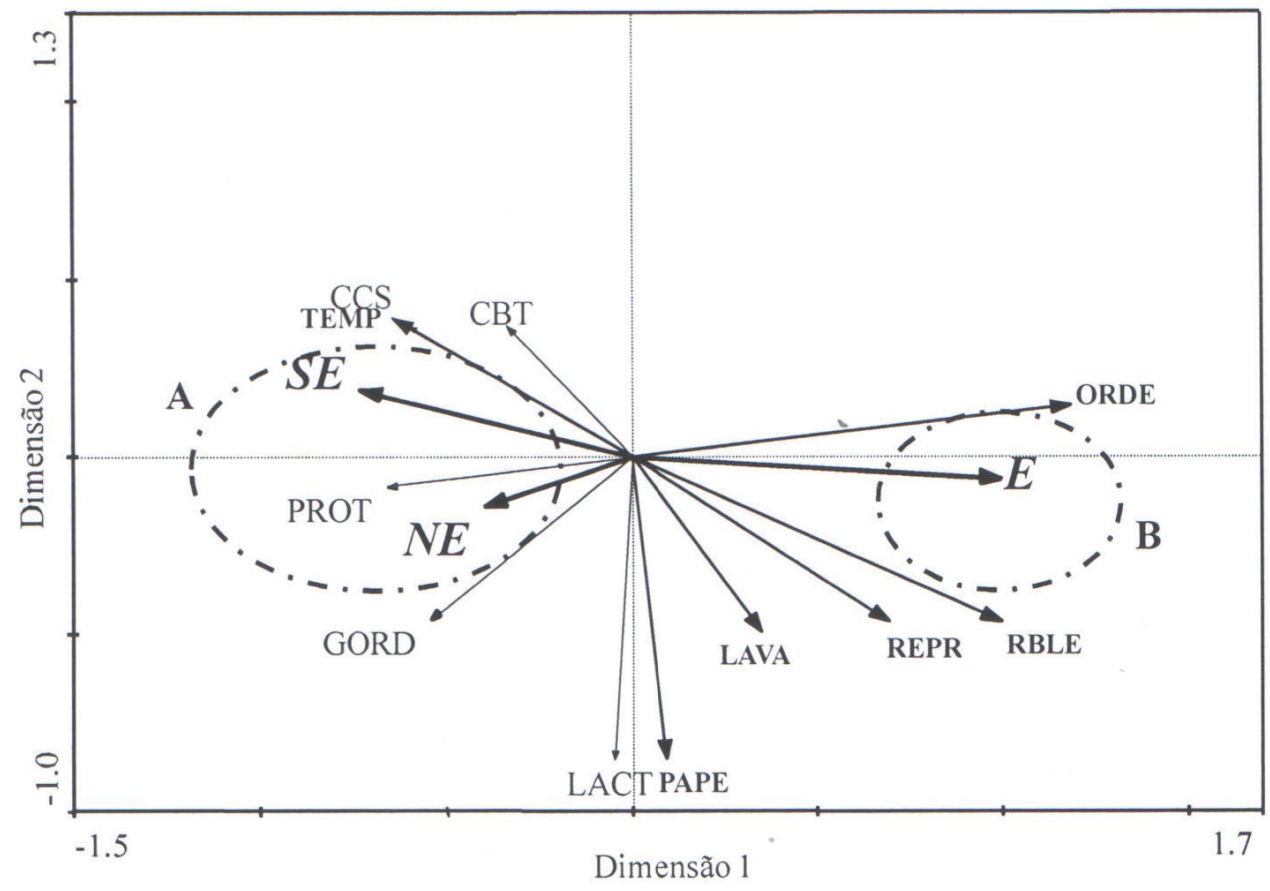

LEGENDA: Variáveis Respostas: PROT - teor de proteína, GORD - teor de gordura, LACT - teor de lactose, CCS - contagem de células somáticas e CBT - contagem bacteriana total. Variáveis Explicativs: TEMP - tempo na atividade, ORDE - tipo de ordenha, RBLE - renda bruta com bovinos de leite, REPR - método de reprodução, LAVA - lavagem dos tetos, PAPE - área com pastagem perene.

Fonte: Elaboração dos autores.

Estes dados são corroborados por Zanela et al. (2006), que verificaram que à medida que aumenta o nível de especialização dos sistemas de produção há um aumento do volume de leite, redução da CCS e do teor de gordura e aumento da lactose. Para os níveis de proteína bruta total os pesquisadores não encontraram diferenças significativas.

Para o sistema NE a análise indicou associação com os maiores valores de proteína (PROT) e gordura (GORD) das amostras (Figura 1). Este comportamento está intimamente relacionado à menor produtividade dos animais em sistemas não especializados. Esta relação também foi verificada por Rodas et al. (2000), Gonzalez (2002), Gonzalez et al. (2006) e Zanela et al. (2006), que observaram que quanto menor a produção de leite, maior a percentagem de gordura.
O sistema ES associou-se principalmente aos maiores valores encontrados para as variáveis RBLE (renda bruta com bovino), REPR (método de reprodução) e LAVA (lavagem dos tetos). Isso demonstra que os sistemas especializados realizam investimentos, tanto na área do melhoramento genético do rebanho, como nas técnicas de higiene, o que torna a atividade leiteira uma importante fonte de renda. De acordo com os resultados da pesquisa, onze das quatorze propriedades classificadas como especializadas apresentam o leite como principal fonte de renda. Martins et al. (2007) atribuíram ao menor percentual de mastite verificado em sistemas de produção mais especializados, a obtenção de leite com melhor qualidade.

As variáveis ORDE (tipo de ordenha) e RBLE (renda bruta com bovinos de leite) foram as de 
maior correlação com a parte positiva da dimensão um, enquanto a variável PAPE (área com pastagem perene) correlacionou-se com a parte negativa da dimensão dois (Tabela 3).

Tabela 3. Intersecção das correlações variáveis explicativas com as dimensões da RDA.

\begin{tabular}{ccc}
\hline Variável & Dimensão 1 & Dimensão 2 \\
\hline TEMP & $-0,3453$ & 0,3161 \\
PAPE & 0,0504 & $-0,6979$ \\
RBLE & 0,5366 & $-0,3827$ \\
ORDE & 0,6377 & 0,1159 \\
LAVA & 0,1894 & $-0,4061$ \\
REPR & 0,3738 & $-0,3822$ \\
\hline
\end{tabular}

Nota: TEMP - tempo na atividade, PAPE - área com pastagem perene, RBLE - renda bruta com bovinos de leite, ORDE - tipo de ordenha, LAVA - lavagem dos tetos, REPR - método de reprodução.

Fonte: Elaboração dos autores.

O triplot resultante da Análise de Redundância (RDA) baseado nas variáveis ambientais, variáveis explicativas e nível de especialização expressa claramente a relação existente entre os parâmetros de qualidade do leite e as variáveis selecionadas (Figura 2).

Os autovalores baseados nos parâmetros de qualidade do leite para a RDA nos eixos um, dois e três, respectivamente, foram 0,206, 0,112 e 0,086 (Figura 2). As variáveis selecionadas explicaram $43,9 \%$ dos dados para a qualidade do leite. Destes, $46,9 \%$ estão representados na dimensão um e $25,4 \%$ são representados na dimensão dois. Juntas as dimensões explicam $72,3 \%$ da relação entre variáveis respostas e explicativas. O teste de permutação de Monte Carlo revelou uma relação significativa entre os parâmetros de qualidade do leite e as variáveis explicativas selecionadas $(\mathrm{F}=5,7 ; \mathrm{p}=0,002)$ (TER BRAAK; SMILAUER, 1998), e corrobora com a tendência apresentada pela Análise de Componentes Principais (ACP), isto é, são semelhantes e reforçam os resultados obtidos anteriormente.

A ordenação dos parâmetros de qualidade do leite indicou alta contagem de células somáticas (CCS) associada principalmente com a variável TEMP (tempo na atividade) (Figura 2). Houve correlação significativa entre os parâmetros de qualidade do leite e a variável TEMP $(\mathrm{F}=2,32, \mathrm{p}=0,0052)$. A variável LACT (lactose) correlacionou-se com as variáveis ambientais LAVA (lavagem dos tetos) e PAPE (área com pastagem perene), que apresentaram correlação significativa com os parâmetros de qualidade do leite $(\mathrm{F}=2,01, \mathrm{p}=0,088 ; \mathrm{F}=2,29, \mathrm{p}=0,068$, respectivamente). 
Figura 2. Análise de Redundância: triplot das variáveis respostas, sistemas de produção (E, SE e NE) e variáveis explicativas. Círculos, quadrados e losangos representam, respectivamente, amostras dos sistemas E, SE e NE.

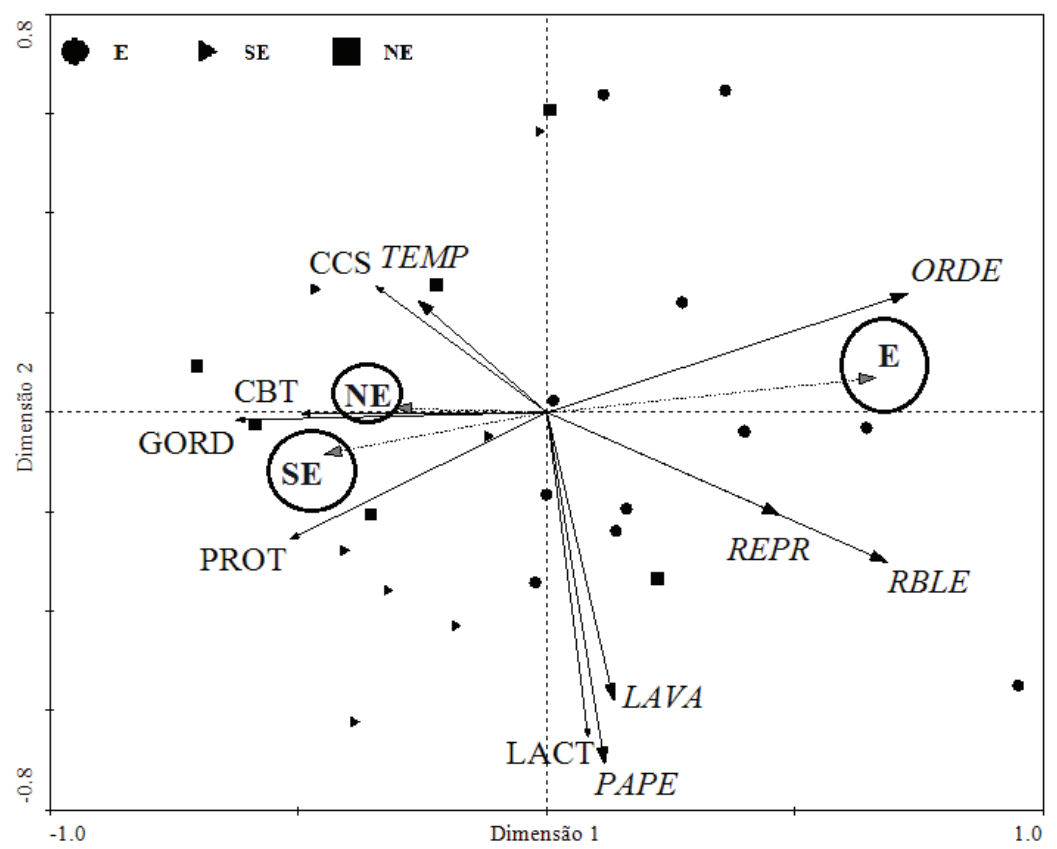

LEGENDA: Variáveis Respostas: PROT - teor de proteína, GORD - teor de gordura, LACT - teor de lactose, CCS - contagem de células somáticas e CBT contagem bacteriana total. Variáveis Explicativas: TEMP - tempo na atividade, ORDE - tipo de ordenha, RBLE - renda bruta com bovinos de leite, REPR - método de reprodução, LAVA - lavagem dos tetos, PAPE - área com pastagem perene.

Fonte: Elaboração dos autores.

Correlações altamente significativas foram encontradas para as variáveis: RBLE (renda bruta com bovinos) e ORDE (tipo de ordenha), que explicam a maior totalidade dos dados de qualidade do leite obtidos no sistema $(\mathrm{F}=4,19, \mathrm{p}=0,004$; $\mathrm{F}=2,37, \mathrm{p}=0,042$, respectivamente). Variáveis como tipo de ordenha (ORDE) e renda bruta com bovinos (RBLE) foram as que mais contribuíram para a parte positiva da dimensão um, enquanto a variável área com pastagem perene (PAPE) foi a que mais contribuiu para a parte negativa da dimensão dois (Tabela 4).
Tabela 4. Intersecção das correlações variáveis explicativas com as dimensões da RDA.

\begin{tabular}{ccc}
\hline Variável & Dimensão 1 & Dimensão 2 \\
\hline TEMP & $-0,2608$ & 0,2249 \\
PAPE & 0,1165 & $-0,7076$ \\
RBLE & 0,6862 & $-0,3012$ \\
ORDE & 0,7276 & 0,2393 \\
LAVA & 0,1351 & $-0,5802$ \\
REPR & 0,4695 & $-0,2067$ \\
\hline
\end{tabular}

Nota: TEMP - tempo na atividade, PAPE - área com pastagem perene, RBLE - renda bruta com bovinos de leite, ORDE - tipo de ordenha, LAVA - lavagem dos tetos, REPR - método de reprodução.

Fonte: Elaboração dos autores. 


\section{Conclusões}

As variáveis explicativas demonstraram que o sistema especializado de produção diferencia-se dos sistemas semiespecializado e não especializado. O aumento do nível de especialização da atividade leiteira, mesmo produzindo menor porcentagem de gordura e proteína no leite, proporciona a obtenção de leite de melhor qualidade, devido aos menores índices de CCS e CBT, associadas principalmente, à maior renda proporcionada pela atividade. Nas propriedades especializadas, a atividade leiteira apresenta maior importância econômica, estimulando o produtor a adotar melhores práticas de higiene na ordenha e de reprodução do rebanho.

\section{Referências}

BAUMGARD, L. H.; MATITASHVILI, E.; CORL, B. A.; DWYER, D. A.; BAUMAN, D. E. Trans-10, cis-12 conjugated linoleic acid decreases lipogenic rates and expression of genes involved in milk lipid synthesis in dairy cows. Journal of Dairy Science, Champaign, v. 85, n. 9, p. 2155-2163, 2002.

BRAMLEY, A. J.; McKINNON, C. H. The microbiology of raw milk. In: ROBINSON, R .K. Dairy microbiology: the microbiology of milk. 2. ed. Barking: Elsevier Science Publishers, 1990. cap. 5, p. 163-208.

BRASIL. Ministério da Agricultura, Pecuária e Abastecimento. Prorrogada mudança na norma de qualidade do leite. Notícias - legislação, 30 jun. 2011. Disponível em: <http://www.agricultura.gov.br/animal/ noticias/2011/06/prorrogada-mudanca-na-norma-dequalidade-do-leite>. Acesso em: 11 dez. 2011.

Regulamento técnico de identidade e qualidade de leite cru refrigerado. Instrução normativa $\mathrm{n}^{\mathrm{o}}$ 51, de 18 de setembro de 2002. Diário Oficial [da] União, 20 set. 2002. Seção 1, p. 13.

FASSIO, L. H.; REIS, R. P.; YAMAGUCHI, L. C. T.; REIS, A. J. dos. Custos e shut-down point da atividade leiteira em Minas Gerais. Revista de Economia e Sociologia Rural, Brasília, v. 43, n. 4, p. 759-777, 2005.

GOMES, A. L.; FERREIRA FILHO, J. B. de S. Economias de escala na produção de leite: uma análise dos Estados de Rondônia, Tocantins e Rio de Janeiro. Revista de Economia e Sociologia Rural, Brasília, v. 45, n. 3, p. 591-619, 2007.

GONZALEZ, F. H. D. Pode o leite refletir o metabolismo da vaca? In: DÜRR, J. W.; CARVALHO, M. P.; SANTOS, M. V. dos. O compromisso com a qualidade do leite no Brasil. Passo Fundo: UPF Editora, 2004. p. 195-209.

Qualidade do leite em diferentes sistemas de produção e meses do ano na bacia leiteira de Pelotas. 2002. Dissertação (Mestrado em Produção Animal) Universidade Federal de Pelotas, Pelotas.

GONZALEZ, H. L.; FISCHER, V.; RIBEIRO, M. E. R.; STUMPF JÚNIOR, W.; GOMES, J. F.; FAGUNDES, C. M.; SILVA, M. A. Comparação da qualidade do leite em diferentes sistemas de produção da bacia leiteira de Pelotas, RS. Revista Brasileira de Agrociência, Pelotas, v. 12, n. 4, p. 475-482, 2006.

HARMON, R. J. Physiology of mastitis and factors affecting somatic cell counts. Journal of Dairy Science, Champaign, v. 77, n. 7, p. 2103-2112, 1994.

KITCHEN, B. J. Review of the progress of dairy science: bovine mastitis: milk compositional changes and related diagnostics test. Journal of Dairy Research, London, v. 48, p. 167-188, 1981.

MARTINS, P. R.; FISCHER, V.; RIBEIRO, M. E. R.; GOMES, J. F.; STUMPF JÚNIOR, W.; ZENALA, M. B. Produção e qualidade do leite em sistemas de produção da região leiteira de Pelotas, RS, Brasil. Ciência Rural, Santa Maria, v. 37, n. 1, p. 212-217, 2007.

MARTINS, P. R.; SILVA, C. A.; FISCHER, V.; RIBEIRO, M. E. R.; STUMPF JÚNIOR, W.; ZENALA, M. B. Produção e qualidade do leite na bacia leiteira de Pelotas-RS em diferentes meses do ano. Ciência Rural, Santa Maria, v. 36, n. 1, p. 209-214, 2006.

PHILPOT, W. N.; NICKERSON, S. C. Mastitis: counter attack - a strategy to combat mastitis. Illinois: Babson Brothers Co, 1991. 150 p.

RIBEIRO, M. E. R.; STUMPF JÚNIOR, W.; BUSS, H. Qualidade de leite. In: BITENCOURT, D.; PEGORARO, L. M. C.; GOMES, J. F. Sistemas de pecuária de leite: uma visão na região de clima temperado. Pelotas: Embrapa Clima Temperado, 2000. p. 175-195.

RODAS, A. C.; ISEPON, J. S.; ALVES, J. B.; ISEPON, O. J. Monitoramento da qualidade do leite "in natura" obtidos por diferentes tipos de manejo em Pereira Barreto (SP). Revista do Instituto de Laticínios Candido Tostes, Juiz de Fora, v. 54, n. 312, p. 19-29, 2000.

SCHAELLIBAUM, M. Efeitos de altas contagens de células somáticas sobre a produção de queijos. In: SIMPÓSIO INTERNACIONAL SOBRE QUALIDADE DO LEITE, 2., 2000, Curitiba. Anais... Curitiba: CIETEP/ FIEP, 2000. p. 21-26.

SILVA, V. A. M.; RIVAS, P. M.; ZANELA, M. B.; 
PINTO, A. T.; RIBEIRO, M. E. R.; SILVA, F. F. P.; MACHADO, M. Avaliação da qualidade físico-química e microbiológica do leite cru, do leite pasteurizado tipo A e de pontos de contaminação de uma Granja Leiteira no RS. Acta Scientiae Veterinariae, Porto Alegre, v. 38, n. 1, p. 51-57, 2010.

TER BRAAK, C. J. F.; PRENTICE, I. C. A theory of gradient analysis. Advances in Ecological Research, v. 18, p. 271-317, 1988.

TER BRAAK, C. J. F.; SMILAEUR, P. Reference manual and user's guide to canoco for windows: Software for canonical community ordination (version 4), Ithaca, New York, USA, Microcomputer Power. 1998. 500 p.

ZANELA, M. B.; FISCHER, V.; RIBEIRO, M. E. R.; STUMPF JÚNIOR, W.; ZANELA, C.; MARQUES, L. T.; MARTINS, P. R. G. Qualidade do leite em sistemas de produção na região Sul do Rio Grande do Sul. Pesquisa Agropecuária Brasileira, Brasília, v. 41, n. 1, p. 153-159, 2006.

ZAR, J. H. Biostatistical analysis. 3rd ed. Upper Saddle River, New Jersey, USA, rentice-Hall International, Inc. 1996. $662 \mathrm{p}$. 